\title{
Candidate effector proteins of the necrotrophic apple canker pathogen Valsa mali can suppress BAX-induced PCD
}

OPEN ACCESS

Edited by:

Maryam Rafiqi,

Computomics GmbH \& Co KG,

Germany

Reviewed by:

Weixing Shan,

Northwest A\&F University, China Kim Marilyn Plummer,

La Trobe University, Australia

*Correspondence:

Lili Huang,

State Key Laboratory of Crop Stress Biology for Arid Areas and College of Plant Protection, Northwest A\&F University, Yangling, Shaanxi 712100 ,

China

huanglili@nwsuaf.edu.cn

t These authors have contributed equally to this work.

Specialty section: This article was submitted to Plant Biotic Interactions, a section of the journal Frontiers in Plant Science

Received: 13 December 2014 Accepted: 13 July 2015 Published: 27 July 2015

Citation:

Li Z, Yin Z, Fan Y, Xu M, Kang Z and Huang $L$ (2015) Candidate effector proteins of the necrotrophic apple canker pathogen Valsa mali can suppress BAX-induced PCD.

Front. Plant Sci. 6:579 doi: 10.3389/fp/s.2015.00579

\section{Zhengpeng Lit, Zhiyuan Yin', Yanyun Fan, Ming Xu, Zhensheng Kang and Lili Huang* \\ State Key Laboratory of Crop Stress Biology for Arid Areas and College of Plant Protection, Northwest A\&F University, Yangling, China}

Canker caused by the Ascomycete Valsa mali is the most destructive disease of apple in Eastern Asia, resulting in yield losses of up to 100\%. This necrotrophic fungus induces severe necrosis on apple, eventually leading to the death of the whole tree. Identification of necrosis inducing factors may help to unravel the molecular bases for colonization of apple trees by $V$. mali. As a first step toward this goal, we identified and characterized the $V$. mali repertoire of candidate effector proteins (CEPs). In total, 193 secreted proteins with no known function were predicted from genomic data, of which 101 were V. mali-specific. Compared to non-CEPs predicted for the V. mali secretome, CEPs have shorter sequence length and a higher content of cysteine residues. Based on transient over-expression in Nicotiana benthamiana performed for 70 randomly selected CEPs, seven V. mali Effector Proteins (VmEPs) were shown to significantly suppress BAX-induced PCD. Furthermore, targeted deletion of VmEP1 resulted in a significant reduction of virulence. These results suggest that $V$. mali expresses secreted proteins that can suppress PCD usually associated with effector-triggered immunity (ETI). ETI in turn may play an important role in the $V$. mali-apple interaction. The ability of $V$. mali to suppress plant ETI sheds a new light onto the interaction of a necrotrophic fungus with its host plant.

Keywords: apple Valsa canker, secreted protein, cell death, virulence factor, plant-fungus interaction

\section{Introduction}

The Apple Valsa canker fungus Valsa mali is a necrotrophic pathogen inducing severe necrosis on apple. It is the most devastating pathogen of apple in Eastern Asia, causing severe yield losses each year (Lee et al., 2006; Li et al., 2013). This pathogen preferentially infects apple although it is also aggressive to other Rosaceae woody plants such as pear, crabapple, apricot and peach (Wang et al., 2011b; Zhou et al., 2014). V. mali is considered a necrotroph that completes its life cycle on dead plant cells killed prior to or during colonization (Ke et al., 2013; Yin et al., 2015). Particularly, genes involved in plant cell wall degradation and toxin synthesis are remarkably expanded in the $V$. mali genome and are commonly up-regulated during infection (Ke et al., 2014; Yin et al., 2015). However, it is becoming more and more evident that interactions between necrotrophs and their hosts are considerably more complex and subtle than previously thought. Functional analysis of the $V$. mali genome showed that 193 secreted proteins have no known annotation, of which about 101 are $V$. mali-specific. Given that phytopathogens 
often secrete a series of proteins into the host-pathogen interface to manipulate host cell physiology and ultimately promote infection, functional verification of these secreted proteins is of particular interest for identifying potential virulence factors.

Effectors play an important role in the host-pathogen interface during infection (Giraldo and Valent, 2013; Vleeshouwers and Oliver, 2014). It is generally accepted that biotrophs actively suppress programmed cell death (PCD) of the host, whereas necrotrophs are believed to promote cell death to enhance colonization (Donofrio and Raman, 2012; Mengiste, 2012). Typically, most of the known effectors secreted by necrotrophic fungi (e.g., Parastagonospora nodorum, Pyrenophora tritici-repentis, Alternaria alternata, or Cochliobolus heterostrophus) lead to effector-triggered susceptibility (ETS) resulting in host cell death (reviewed in Wang et al., 2014). Intriguingly, the effector protein SSITL of Sclerotinia sclerotiorum can suppress the jasmonic/ethylene (JA/ET) signaling pathway mediated resistance at an early stage of infection (Zhu et al., 2013). In addition, oxalic acid secreted by $S$. sclerotiorum inhibits host autophagy which constitutes an effective defense response in this necrotrophic fungus-plant interaction (Kabbage et al., 2013). These evidences suggest that effectors of necrotrophic fungi may also suppress host defense responses, rather than induce cell death.

Programmed cell death triggered in plants by the proapoptotic mouse protein BAX physiologically resembles PCD associated with defense-related HR (Lacomme and Santa Cruz, 1999). As a result, the ability to suppress BAX-triggered PCD has proven a valuable initial screen for pathogen effectors capable of suppressing defense-associated PCD (Abramovitch et al., 2003; Dou et al., 2008; Wang et al., 2011a).

As a first step toward elucidating the molecular basis for colonization of apple by $V$. mali, we identified and characterized the $V$. mali repertoire of candidate effectors. Out of 70 randomly selected candidate effector proteins (CEPs), seven were able to suppress BAX-induced PCD in Nicotiana benthamiana. Furthermore, functional characterization of $\mathrm{VmEP} 1$ revealed that this candidate effector is a true virulence factor of $V$. mali. Taken together, the candidate effectors identified here provide valuable information for the study of the $V$. mali-apple interaction. Suppression of effector-triggered immunity (ETI) by this necrotrophic pathogen provides new insights into the interaction of a necrotrophic fungus and its host plant.

\section{Materials and Methods}

\section{Strains and Culture Conditions}

Valsa mali strain $03-8$ is a stock culture of the Laboratory of Integrated Management of Plant Diseases at the College of Plant Protection, Northwest A\&F University, Yangling, PRC (Available on request). Cultures were maintained on potato dextrose agar (PDA) medium with a layer of cellophane at $25^{\circ} \mathrm{C}$ in the dark. Agrobacterium tumefaciens strain GV3101 used for molecular cloning and agro-infiltration experiments was cultured on Luria-Bertani medium at $28^{\circ} \mathrm{C}$. $N$. benthamiana plants were maintained at $25^{\circ} \mathrm{C}$ with $16 \mathrm{~h}$ illumination per day.

\section{Construction of $\boldsymbol{V}$. mali cDNA Libraries}

Total RNA was extracted using the RNeasy Micro kit (Qiagen, Shenzhen, PRC) according to the manufacturer's protocol from (a) V. mali mycelium grown on PDA medium for 3 days, and (b) apple twigs of Malus domestica borkh. cv. 'Fuji' inoculated with V. mali mycelium [3 days post inoculation (dpi)]. First strand cDNA was synthesized by the RevertAid ${ }^{\mathrm{TM}}$ First Strand cDNA Synthesis Kit (Fermentas, Shenzhen, PRC) according to the manufacturer's protocol.

\section{Sequence Analyses}

The secretome of $V$. mali was obtained from the sequenced genome in our previous study (Yin et al., 2015). The WholeGenome Shotgun project for $V$. mali has been deposited at DDBJ/EMBL/GenBank under the accession JUIY01000000. CEPs were defined as extracellular proteins with no known function (e-value $>1 \mathrm{e}-5)$. Cysteine content was calculated using the pepstats program from the EMBOSS package (http://emboss. bioinformatics.nl/). Markov clustering analysis was performed using tribe-MCL (Enright et al., 2002). The known effector motifs RXLR (Kale et al., 2010), [L/I]xAR (Godfrey et al., 2010), YxSL[R/K] (Saunders et al., 2012), [R/K]VY[L/I]R (Ridout et al., 2006), and [Y/F/W]xC (Dodds et al., 2009) were searched for using the fuzzpro program from the EMBOSS package. Nuclear localization signals (NLSs) were predicted with NLStradamus (Ba et al., 2009). De novo motif search was performed using MEME (Bailey et al., 2009).

\section{Plasmid Constructs}

Targeted genes were amplified from the cDNA library using high-fidelity TransStart ${ }^{\circledR}$ FastPfu DNA polymerase (TransStart, Beijing, PRC). For A. tumefaciens infiltration assays in $N$. benthamiana, PCR products were digested with the appropriate restriction enzymes and ligated into the PVX vector pGR106 (Giraldo and Valent, 2013). Primers used for PCR are listed in Supplementary Table S1. All plasmids were confirmed by sequencing.

\section{Agrobacterium tumefaciens Infiltration Assays}

Agro-infiltration assays were carried out following the previously described procedure (Dou et al., 2008). For transient expression, A. tumefaciens strain GV3101 carrying an expression plasmid (pGR106:effector) was grown in LB medium containing kanamycin $(50 \mu \mathrm{g} / \mathrm{ml})$. Cells were resuspended in $10 \mathrm{mM} \mathrm{MgCl}_{2}$ $\left(\mathrm{pH}\right.$ 5.6) and cell density was adjusted to an $\mathrm{OD}_{600}=0.4$. Bacteria were infiltrated through a little nick with a syringe to the upper leaves of 4-week-old $N$. benthamiana plants. A. tumefaciens cells carrying the Bax gene (pGR106:Bax) were infiltrated into the same site just subsequently, or $16 \mathrm{~h}$ later. As control, plants were infiltrated with A. tumefaciens carrying an empty PVX vector. Cell death symptoms were evaluated and photographed 3-4 days past infiltration. Each assay was performed in triplicate.

\section{RNA Extraction and Transcript Level Analysis}

To measure transcript level of candidate effector genes by qRT-PCR, apple tissue infected with $V$. mali strain $03-8$ was 
sampled at $0,6,12,24,36$, and 48 hours post inoculation (hpi). Total RNA was extracted using the RNAeasy ${ }^{\circledR}$ Plant mini kit (Qiagen, Shenzhen, PRC) following the recommended protocol. First-strand cDNA was synthesized using an RT-PCR system (Promega, Madison, WI, USA) following the manufacturer's instructions. SYBR green $\mathrm{qRT}$-PCR assays were performed to analyze transcript levels. $V$. mali housekeeping gene G6PDH was used as endogenous control (Yin et al., 2013). Data from three biological replicates were used to calculate the mean and standard deviation. Primers used for qRT-PCR were listed in Supplementary Table S3.

\section{Generation of VmEP1 Mutants}

A typical reaction assembling three components using the hygromycin B phosphotransferase gene $(h p h)$ as a selective marker. The $h p h$ gene was amplified with primers, HPH-F ( $5^{\prime}$ GGCTTGGCTGGAGCTAGTGGAGGTCAA- $3^{\prime}$ and HPH-R $5^{\prime}$ AACCCGCGGTCGGCATCTACTCTATTC-3') from pBIG2RH PH2-GFP-GUS. The upstream $(\sim 1,100 \mathrm{bp})$ and downstream $(\sim 1,400$ bp) flanking sequences of $V m E P 1$ were amplified using primer pairs VmEP1-1F/2R and VmEP1-3F/4R, respectively. Then the deletion cassette was generated by double-joint PCR as described (Yu et al., 2004), using the primer pair VmEP1-CF/CR. For generating deletion mutants, the $V m E P 1$ gene-replacement construct was transformed into protoplasts of $V$. mali as previously described (Gao et al., 2011). Putative deletion mutants were verified by PCR using four primer pairs (VmEP15F/6R, VmEP1-7F/H855R, VmEP1-H856F/8R, and H850/H852) to detect target gene $(\sim 850 \mathrm{bp})$, upstream $(\sim 1,100 \mathrm{bp})$, and downstream $(\sim 1,400 \mathrm{bp})$ region, and the $h p h$ gene $(\sim 750 \mathrm{bp})$, respectively. Subsequently, deletion mutants were confirmed by Southern blot hybridization using the DIG DNA Labeling and Detection Kit II (Roche, Mannheim, Germany) according to the manufacturer's instructions. Primers used for gene deletion are listed in Supplementary Table S2.

\section{Complementation of the $\Delta V m E p 1$ Mutant}

A fragment containing the entire $V m E p 1$ gene without the termination codon and its promoter $(\sim 1.5 \mathrm{~kb})$ was amplified with primers VmEp1-FL2-F/R ( $5^{\prime}$-cgactcactatagggcg aattgggtactcaaattggTTTATCTCAATCGCCTCGTT-3' and $5^{\prime}$-ca ccaccceggtgaacagctcctcgccettgctcacGTCTACCGAACATGTCT GTGG-3'), and cloned into plasmid pFL2 by the yeast gap repair approach (Bruno et al., 2004; Zhou et al., 2012). The resulting construct, pFL2-VmEp1, was transformed into protoplasts of the $\triangle V m E p 1$ mutants $74 \#$ and $85 \# . \triangle V m E p 1 / V m E p 1$ transformants were confirmed by PCR using the primer pair VmEP1-5F/6R. The $\triangle V m E p 1 / V m E p 1$ complemented transformants $74 \#-1$ and 85\#-1were selected for phenotypic analysis.

\section{Vegetative Growth, Conidiation, and Pathogenicity of Mutants}

Vegetative growth and conidiation was examined at three and 40 days, respectively. For our pathogenicity assay, detached apple twigs of Malus domestica borkh. cv. 'Fuji' were inoculated with $V m E P 1$ deletion mutants, $\triangle V m E p 1 / V m E p 1$ complementation mutants, and wild type as described (Oliva et al., 2010). All treatments were performed with at least ten replicates, and all experiments were repeated three times. Data were analyzed by Student's $t$-test using the SAS software package (SAS Institute, Cary, NC, USA).

\section{Epifluorescence Microscopy}

To measure the level of colonization by the VemEP1-deletion mutants, boundary-zones $\left(\sim 0.5 \mathrm{~cm}^{2}\right)$ of inoculated leaves were sampled at $60 \mathrm{hpi}$ and treated with $1 \mathrm{M} \mathrm{KOH}$ solution for $15 \mathrm{~min}$ at $121^{\circ} \mathrm{C}$. After cooling to room temperature, the samples were washed in distilled water twice and then stained in a staining solution (0.067 $\mathrm{M} \mathrm{K}_{2} \mathrm{HPO}_{4}+0.05 \%$ aniline blue) according to Hood and Shew (1996). Leaf samples were examined under a Zeiss epifluorescence microscope (excitation $485 \mathrm{~nm}$, dichronic mirror $510 \mathrm{~nm}$, barrier $520 \mathrm{~nm}$ ). Wild type strain 03-8 was used as control. All treatments were performed with at least five replicates, and all experiments were repeated three times.

\section{Results}

\section{Characterization of Candidate Effector Proteins of $V$. mali}

Considering that pathogen effector repertoires are typically lineage-specific, we defined CEPs as predicted extracellular proteins with no known function (e-value threshold $>1 \mathrm{e}-5$ ). Among the 779 secreted proteins predicted from the $V$. mali genome (Yin et al., 2015), we identified 193 CEPs, of which 101 are $V$. mali-specific. Analysis of amino acid sequences revealed that $V$. mali CEPs have several commonly known properties of effector proteins. They have shorter sequence length relative to non-CEPs, with an average of 233 amino acids, and are also cysteine rich (Figure 1). Markov clustering suggests that there is no obvious expansion of $V$. mali CEP families, and most families contain only one member.

Search for conserved motifs in these 193 CEPs showed that 71 of them contain a total of $97 \mathrm{Y} / \mathrm{F} / \mathrm{WxC}$ motifs, 22 contain $26 \mathrm{~L} / \mathrm{IxAR}$ motifs, and seven contain a single RxLR motif each.

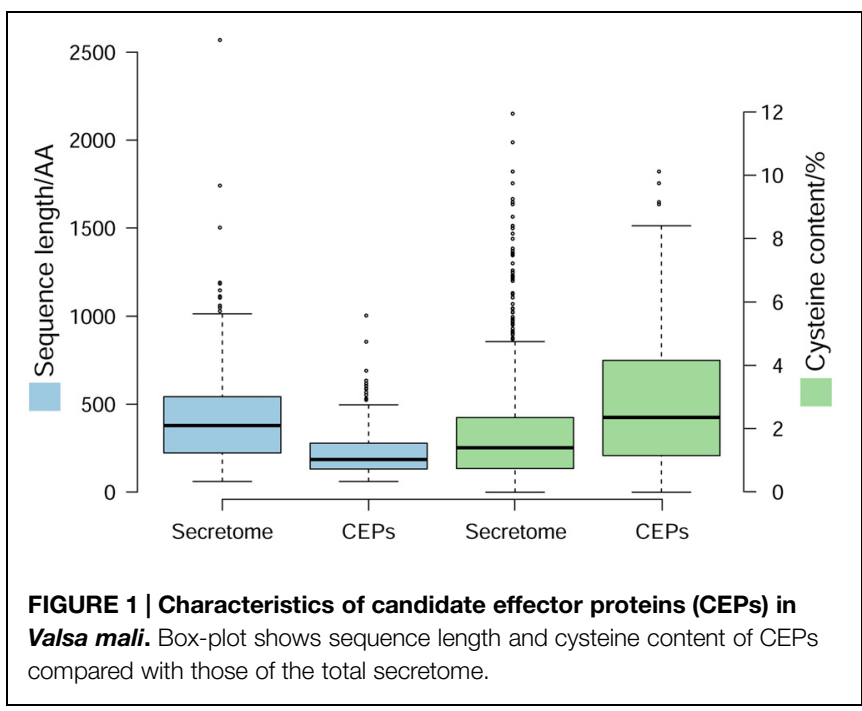


No additional conserved motifs were identified by de novo prediction. In addition, nine CEPs are predicted to contain NLSs.

\section{CEPs of $V$. mali Suppress BAX-induced PCD in N. benthamiana}

Phytopathogen effectors often induce a phenotype upon overexpression in planta, reflecting their virulence activity. To investigate the function of the CEPs of $V$. mali, we tested the ability of CEPs to induce cell death, or to suppress BAX-induced PCD in N. benthamiana. Based on transient over-expression in $N$. benthamiana performed for 70 randomly selected CEPs, seven $V$. mali Effector Proteins (VmEPs) significantly suppressed BAXinduced PCD. Others had little or no effect on suppressing PCD (Figure 2). In addition, all 70 CEPs tested could not induce cell death in $N$. benthamiana. Of these 7 VmEPs, VM1G_05336 is $V$. mali-specific and the others are hypothetical proteins that have homologs in GenBank NR database. Intriguingly, VmEP1 (VM1G_02400) contained a HeLo domain (Table 1) that is exclusively in the fungal kingdom and is similar as other cell death and apoptosis-inducing domains (Fedorova et al., 2005).

\section{Transcription Level of V. mali Candidate Effector Genes}

Fungal effector proteins are generally characterized by specific expression during invasion of plant cells. The expression levels of the $7 \mathrm{VmEP}$ genes identified above were assayed by qRT-PCR with housekeeping gene G6PDH as control (Figure 3). Result showed that 5 of the $7 \mathrm{VmEP}$ genes were up-regulated (fold change $>2$ ) during infection. Particularly, the $V$. mali-specific VM1G_05336 was remarkably induced at 6 and 24 hpi.

\section{Candidate Effector VmEP1 is a Virulence Factor of $\boldsymbol{V}$. mali}

To investigate the function of VmEPs, the putative necrosisinducing protein VmEP1 (VM1G_02400) and the V. malispecific VM1G_05336 were chosen for further study. Gene deletion was performed using a gene replacement strategy (Figure 4A). However, only deletion mutants of VmEP1 were obtained. Among the resulting 125 hygromycin-resistant transformants of $V m E P 1$, two were identified by PCR analysis (Figure 4B). These two VmEp1 deletion mutants (74\# and 85\#)

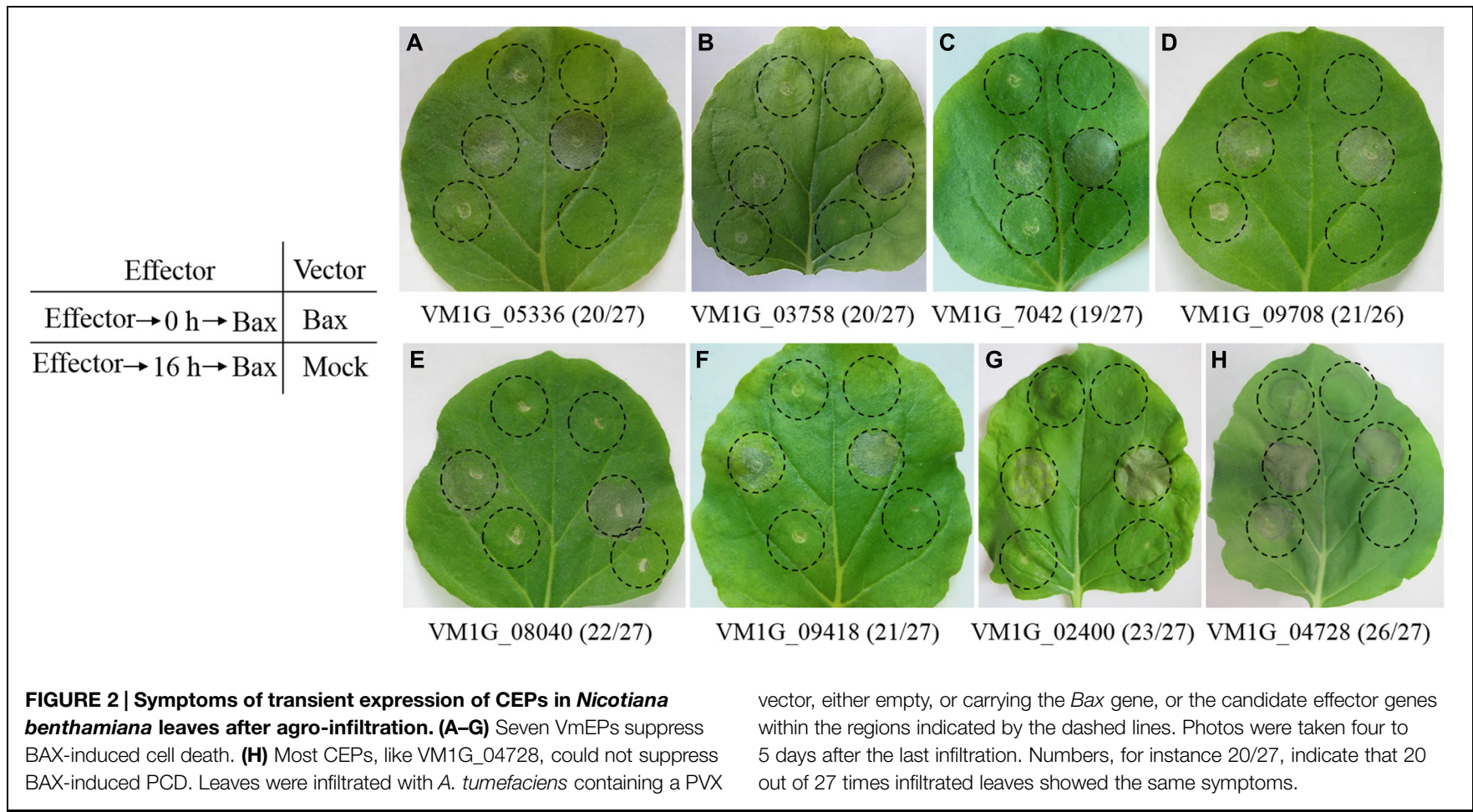

TABLE 1 | Sequence information of Valsa mali effector proteins (VmEPs).

\begin{tabular}{|c|c|c|c|c|c|}
\hline Gene_ID & Accession No. & Description & Length/AA & Cysteine content & Pfam domain \\
\hline VM1G_02400 & KR868746 & Hypothetical protein & 370 & 8 & HeLo (PF14479) \\
\hline VM1G_03758 & KR868747 & Hypothetical protein & 134 & 2 & NA \\
\hline VM1G_05336 & KR868748 & NA & 101 & 2 & NA \\
\hline VM1G_07042 & KR868749 & Hypothetical protein & 330 & 4 & NA \\
\hline VM1G_08040 & KR868750 & Hypothetical protein & 272 & 1 & Peroxidase 2 (PF01328) \\
\hline VM1G_09418 & KR868751 & Hypothetical protein & 205 & 2 & NA \\
\hline VM1G_09708 & KR868752 & Hypothetical protein & 285 & 3 & NA \\
\hline
\end{tabular}




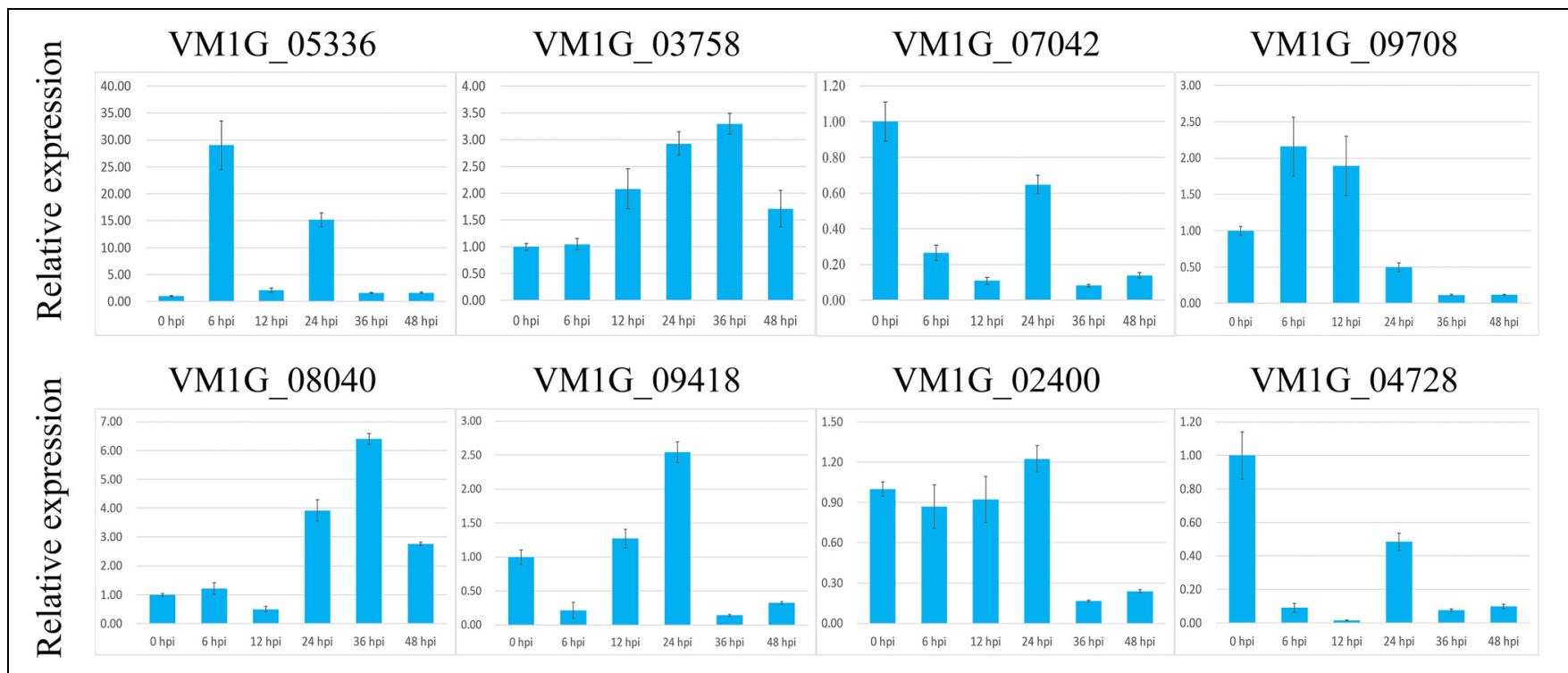

FIGURE 3 | Relative expression level of VmEps at 0, 6, 12, 24, 36, and 48 hours post inoculation (hpi) using reference gene G6PDH for normalization. Results are presented as a mean fold change in relative expression compared to the 0 hpi sampling stage. All experiments were repeated three times. Error bars indicate SEM.

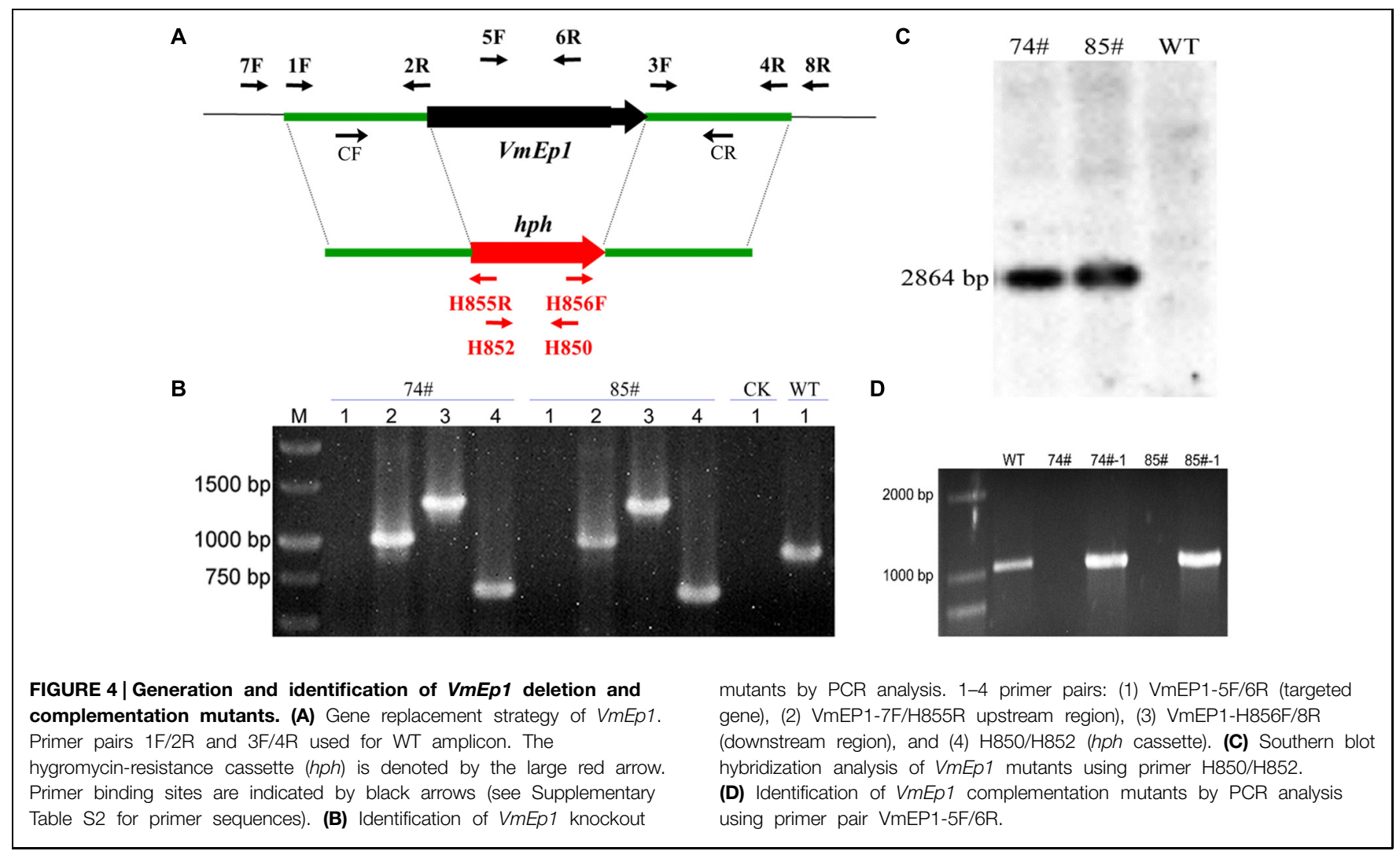

were further confirmed by Southern hybridization (Figure 4C). Complementation of both mutants using a VmEp1 expressing plasmid was again confirmed by PCR using the primer pair VmEP1 5F/6R (Figure 4D). VmEp1 deletion mutants showed no effect on vegetative growth and conidiation on PDA medium
(Figure 5). Intriguingly, pathogenicity assays showed that both deletion mutants had significantly reduced virulence on apple twigs and leaves (Figure 6). $\Delta V m E p 1 / V m E p 1$ complemented mutants 74\#-1 and 85\#-1 exhibit similar virulence as the wild type isolate 03-8 (Figure 6). Results from epifluorescence microscopy 

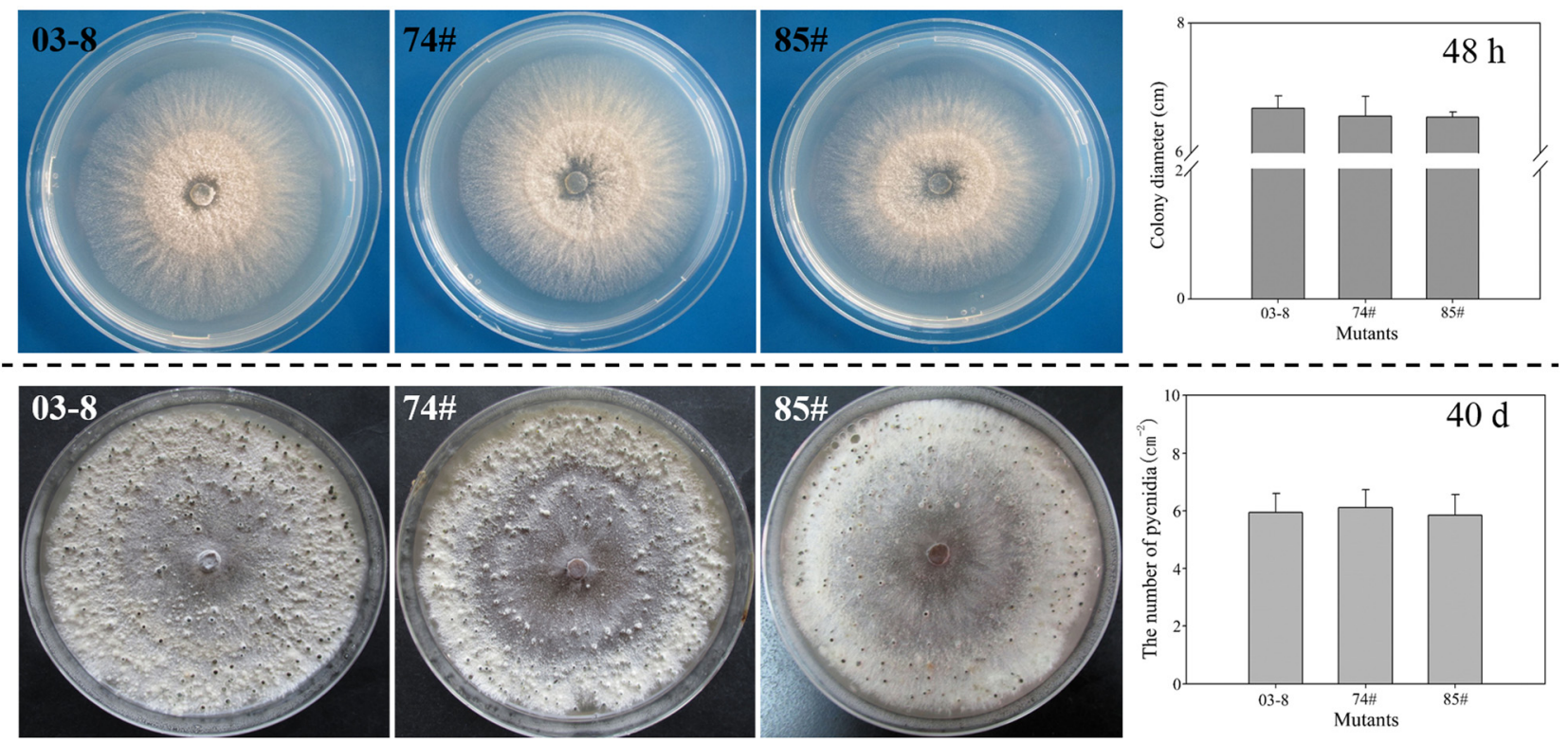

FIGURE 5 | Impact of VmEp1 deletion on vegetative growth and conidiation. Wild-type (03-8), and VmEp1 deletion mutants (74\#) and (85\#) were grown on PDA for $48 \mathrm{~h}$ or 40 days at $25^{\circ} \mathrm{C}$. Colony diameter and number of mature pycnidia were counted. Bars indicate standard deviation of the mean of 30 individual dishes. The experiment was repeated three times.

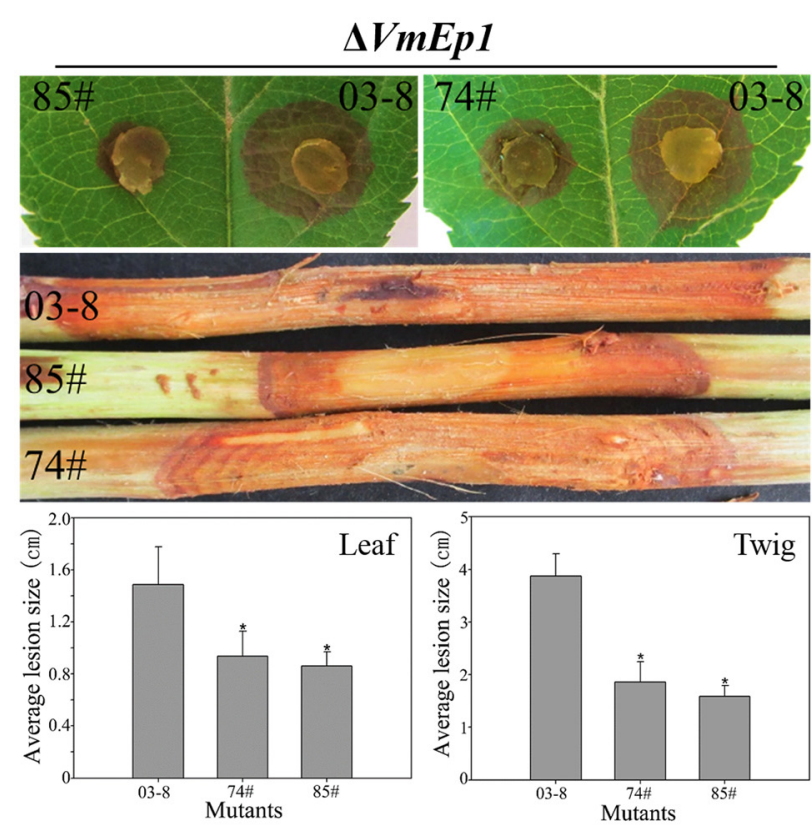

FIGURE 6 | Pathogenicity of mutants. Wild-type (03-8), VmEp1 deletion mutants (74\#) and (85\#), and complementation mutants (74\#-1) and (85\#-1) were inoculated on leaves and twigs of Malus domestica borkh. cv. 'Fuji' for

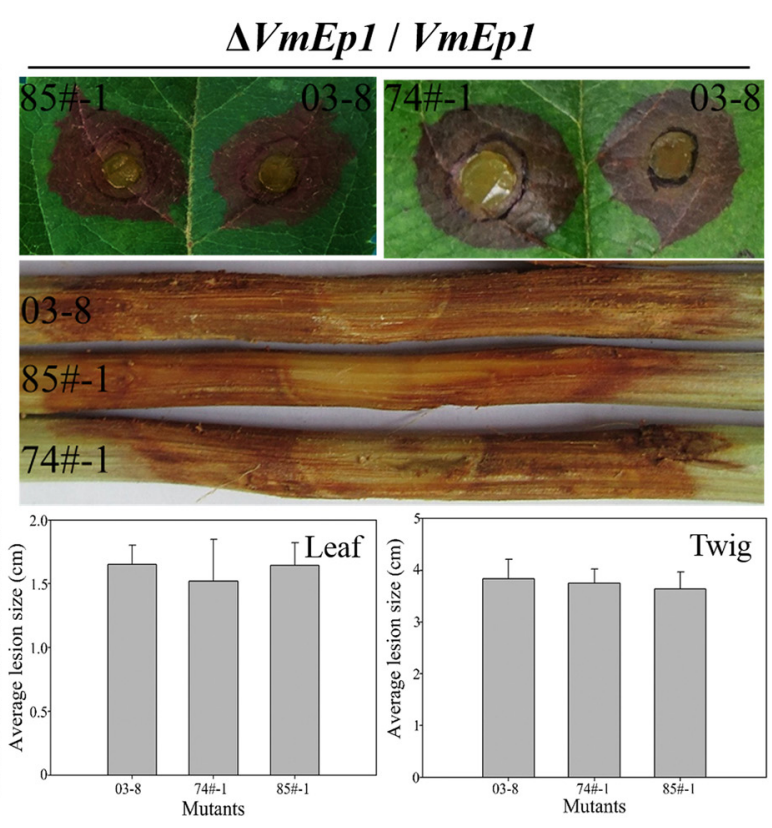

$60 \mathrm{~h}$, or 5 days, respectively. Asterisk represents a significant difference in pathogenicity $(P<0.05)$. Bars indicate standard deviation of the mean of 30 individual host plants. The experiment was repeated three times. show that deletion mutants have reduced mycelia growth within the leaf compared to the wild type which can be rescued by introducing the complementing plasmids (Figure 7). These results indicate that $V m E p 1$ is undoubtedly involved in virulence of $V$. mali.

\section{Discussion}

In the genome of $V$. mali, we previously identified 193 genes encoding secreted proteins with no known function (Yin et al., 2015). In this study, we identified seven V. mali Effector Protein 


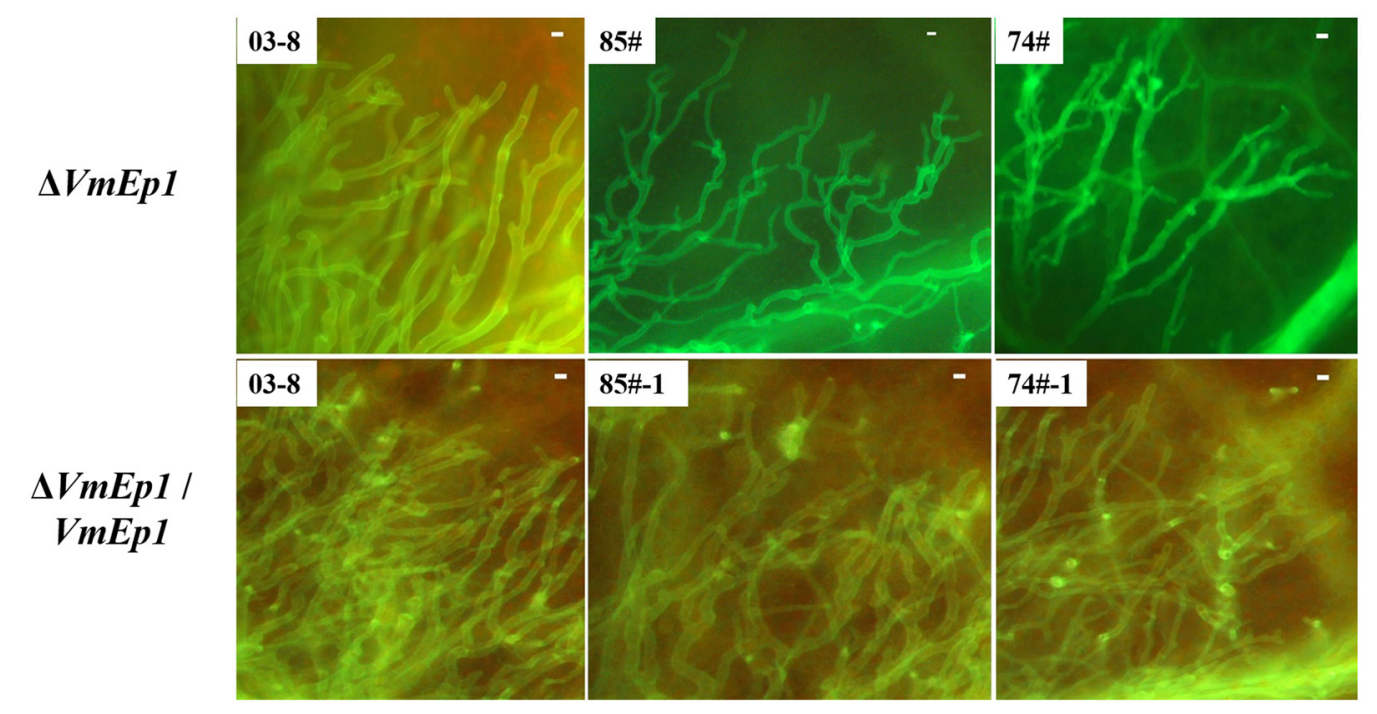

FIGURE 7 | Epifluorescence microscopy of tissue colonization during infection. Boundary-zones $\left(\sim 0.5 \mathrm{~cm}^{2}\right)$ of inoculated leaves were sampled at 60 hpi. All treatments were performed with at least five replicates, and all experiments were repeated three times. Bar $=10 \mu \mathrm{m}$.

(VmEP) genes by a functional screen of these proteins, based on a virus in planta over-expression system. We showed that transient expression of each of these seven VmEPs significantly suppressed BAX-induced PCD in N. benthamiana, five genes of which were up-regulated during infection. While the ability to suppress BAXtriggered PCD is a valuable initial screen for pathogen effectors (Wang et al., 2011a), for it physiologically resembles defenserelated HR (Lacomme and Santa Cruz, 1999), this result strongly suggests that $V$. mali expresses secreted proteins during plant infection, which can suppress effector-triggered plant immunity (ETI) responses in the host.

Effectors of necrotrophic pathogens interact with their host in a gene-for-gene relationship to initiate disease, which leads to ETS (Jones and Dangl, 2006; Oliver and Solomon, 2010; Wang et al., 2014). The host specific toxins secreted by Cochliobolus victoriae are translocated into plant cells to interact with specific corresponding host proteins to promote host cell death (Donofrio and Wilson, 2014; Kuhn and Panstruga, 2014). Likewise, the proteinaceous host specific toxin PtrToxA produced by $P$. triticirepentis targets a host chloroplastic protein, which disrupts the photosynthetic capacity and triggers PCD (Stergiopoulos et al., 2013; Petre and Kamoun, 2014). Indeed, most of the identified effectors of necrotrophic pathogens are found to promote host cell death (Wang et al., 2014). However, because we screened these effector candidates on non-host $N$. benthamiana, seven out of 70 examined candidate effectors of $V$. mali suppress BAXinduced PCD and not a single one was found to induce PCD in $N$. benthamiana. Considering that many effectors of necrotrophic pathogen are host-specific toxins, it is necessary to examine ability of these CEPs to induce necrosis on hosts to determine whether they could be proteinaceous toxins.

Recently, the classic necrotrophic fungus S. sclerotiorum was found to have a biotrophic phase at the very early stage of infection (Kabbage et al., 2013). Oxalic acid secreted by this fungus can suppress host autophagy which is a defense response in its interaction with its host. Indeed, S. sclerotiorum suppresses the defense-related autophagy/PCD at an early stage of infection, and promotes disease-related apoptosis/PCD after infection established (Kabbage et al., 2013). This means that not all forms of cell deaths are equivalent. One type of cell death may be suppressed by a necrotrophic pathogen to inhibit plant defense responses, while another may be promoted to facilitate disease progress. The effectors identified in this study in $V$. mali probably participate in the suppression of defenserelated PCD. Nevertheless, the interaction targets of these effector proteins in apple need to be determined to verify their exact roles in $V$. mali-apple interaction. Especially for VmEP1, because targeted deletion of $V m E P 1$ gene results in a significant reduction in virulence.

As a necrotrophic fungus, $V$. mali is thought to contain virulence factors that induce cell death. Particularly, the impressive arsenal of plant cell wall degrading enzymes and secondary metabolites may account for the severe necrosis observed on apple bark (Yin et al., 2015). Deletion of six pectinase genes significantly reduced virulence of $V$. mali (Yin et al., 2015). Phytotoxic small polypeptides secreted by the closely related peach canker pathogens Leucostoma persoonii and L. cincta can only induce stem necrosis on host plants, reflecting a host specific characteristic (Svircev et al., 1991). In addition, V. mali also possesses homologs of necrosis-inducing factors including NPP1, Ecp2, and Epl (Yin et al., 2015). Likewise, these potential virulence factors also need to be functionally verified.

\section{Author Contributions}

ZL and ZY contributed equally to this work as first authors. LH designed and managed the project. ZL, YF, and MX performed 
the experimental work. ZY performed all the computational analysis. ZL, ZY, ZK, and $\mathrm{LH}$ wrote the paper.

\section{Acknowledgments}

This work was financially supported by the National Natural Science Foundation of China (No. 31471732, 31171796), the Program for Agriculture (nyhyzx20120303403) and the 111 Project (B07049). Authors wish to thank

\section{References}

Abramovitch, R. B., Kim, Y. J., Chen, S., Dickman, M. B., and Martin, G. B. (2003). Pseudomonas type III effector AvrPtoB induces plant disease susceptibility by inhibition of host programmed cell death. EMBO J. 22, 60-69. doi: 10.1093/emboj/cdg006

Ba, A. N. N., Pogoutse, A., Provart, N., and Moses, A. M. (2009). NLStradamus: a simple Hidden Markov Model for nuclear localization signal prediction. BMC Bioinformatics 10:202. doi: 10.1186/1471-2105-10-202

Bailey, T. L., Boden, M., Buske, F. A., Frith, M., Grant, C. E., Clementi, L., et al. (2009). MEME SUITE: tools for motif discovery and searching. Nucleic Acids Res. 37, W202-W208. doi: 10.1093/nar/gkp335

Bruno, K. S., Tenjo, F., Li, L., Hamer, J. E., and Xu, J.-R. (2004). Cellular localization and role of kinase activity of PMK1 in Magnaporthe grisea. Eukaryot. Cell 3, 1525-1532. doi: 10.1128/EC.3.6.1525-1532.2004

Dodds, P. N., Rafiqi, M., Gan, P. H., Hardham, A. R., Jones, D. A., and Ellis, J. G. (2009). Effectors of biotrophic fungi and oomycetes: pathogenicity factors and triggers of host resistance. New Phytol. 183, 993-1000. doi: 10.1111/j.14698137.2009.02922.x

Donofrio, N. M., and Raman, V. (2012). Roles and delivery mechanisms of fungal effectors during infection development: common threads and new directions. Curr. Opin. Microbiol. 15, 692-698. doi: 10.1016/j.mib.2012. 10.004

Donofrio, N. M., and Wilson, R. A. (2014). Redox and rice blast: new tools for dissecting molecular fungal-plant interactions. New Phytol. 201, 367-369. doi: 10.1111/nph.12623

Dou, D., Kale, S. D., Wang, X., Chen, Y., Wang, Q., Wang, X., et al. (2008). Conserved C-terminal motifs required for avirulence and suppression of cell death by Phytophthora sojae effector Avr1b. Plant Cell 20, 1118-1133. doi: 10.1105/tpc.107.057067

Enright, A. J., van Dongen, S., and Ouzounis, C. A. (2002). An efficient algorithm for large-scale detection of protein families. Nucleic Acids Res. 30, 1575-1584. doi: 10.1093/nar/30.7.1575

Fedorova, N. D., Badger, J. H., Robson, G. D., Wortman, J. R., and Nierman, W. C. (2005). Comparative analysis of programmed cell death pathways in filamentous fungi. BMC Genomics 6:177. doi: 10.1186/1471-216 4-6-177

Gao, J., Li, Y., Ke, X., Kang, Z., and Huang, L. (2011). Development of genetic transformation system of Valsa mali of apple mediated by PEG. Acta Microbiol. Sin. 51, 1194-1199.

Giraldo, M. C., and Valent, B. (2013). Filamentous plant pathogen effectors in action. Nat. Rev. Microbiol. 11, 800-814. doi: 10.1038/nrmicr o3119

Godfrey, D., Bohlenius, H., Pedersen, C., Zhang, Z., Emmersen, J., and ThordalChristensen, H. (2010). Powdery mildew fungal effector candidates share N-terminal Y/F/WxC-motif. BMC Genomics 11:317. doi: 10.1186/1471-216411-317

Hood, M. E., and Shew, H. D. (1996). Applications of KOH-aniline blue fluorescence in the study of plant-fungal interactions. Phytopathology 86, 704708. doi: 10.1094/Phyto-86-704

Jones, J. D., and Dangl, J. L. (2006). The plant immune system. Nature 444, 323-329. doi: 10.1038/nature05286

Kabbage, M., Williams, B., and Dickman, M. B. (2013). Cell death control: the interplay of apoptosis and autophagy in the pathogenicity of Sclerotinia
Fengming Song (Zhejiang University, China) for providing the pBIG2RHPH2-GFP-GUS plasmid and Dr. Ralf T. Voegele at Universität Hohenheim for proofreading this manuscript.

\section{Supplementary Material}

The Supplementary Material for this article can be found online at: http://journal.frontiersin.org/article/10.3389/fpls.2015.00579

sclerotiorum. PLoS Pathog. 9:e1003287. doi: 10.1371/journal.ppat.10 03287

Kale, S. D., Gu, B., Capelluto, D. G., Dou, D., Feldman, E., Rumore, A., et al. (2010). External lipid PI3P mediates entry of eukaryotic pathogen effectors into plant and animal host cells. Cell 142, 284-295. doi: 10.1016/j.cell.2010. 06.008

Ke, X., Huang, L., Han, Q., Gao, X., and Kang, Z. (2013). Histological and cytological investigations of the infection and colonization of apple bark by Valsa mali var. mali. Australas. Plant Pathol. 42, 85-93. doi: 10.1007/s13313012-0158-y

Ke, X., Yin, Z., Song, N., Dai, Q., Voegele, R. T., Liu, Y., et al. (2014). Transcriptome profiling to identify genes involved in pathogenicity of Valsa mali on apple tree. Fungal Genet. Biol. 68, 31-38. doi: 10.1016/j.fgb.2014.04.004

Kuhn, H., and Panstruga, R. (2014). Introduction to a virtual special issue on phytopathogen effector proteins. New Phytol. 202, 727-730. doi: $10.1111 /$ nph.12804

Lacomme, C., and Santa Cruz, S. (1999). Bax-induced cell death in tobacco is similar to the hypersensitive response. Proc. Natl. Acad. Sci. U.S.A. 96, 79567961. doi: 10.1073/pnas.96.14.7956

Lee, D. H., Lee, S. W., Choi, K. H., Kim, D. A., and Uhm, J. Y. (2006). Survey on the occurrence of apple diseases in Korea from 1992 to 2000. Plant Pathol. J. 22, 375-380. doi: 10.5423/PPJ.2006.22.4.375

Li, Z., Gao, X., Du, Z., Hu, Y., Kang, Z., and Huang, L. (2013). Survey of apple Valsa canker in Weibei area of Shaanxi province. Acta Agric. Boreali Occidentalis Sin. $1,029$.

Mengiste, T. (2012). Plant immunity to necrotrophs. Annu. Rev. Phytopathol. 50, 267-294. doi: 10.1146/annurev-phyto-081211-172955

Oliva, R., Win, J., Raffaele, S., Boutemy, L., Bozkurt, T. O., Chaparro-Garcia, A., et al. (2010). Recent developments in effector biology of filamentous plant pathogens. Cell. Microbiol. 12, 705-715. doi: 10.1111/j.1462-5822.2010.0 1471.x

Oliver, R. P., and Solomon, P. S. (2010). New developments in pathogenicity and virulence of necrotrophs. Curr. Opin. Plant Biol. 13, 415-419. doi: 10.1016/j.pbi.2010.05.003

Petre, B., and Kamoun, S. (2014). How do filamentous pathogens deliver effector proteins into plant cells? PLoS Biol. 12:e1001801. doi: 10.1371/journal.pbio.1001801

Ridout, C. J., Skamnioti, P., Porritt, O., Sacristan, S., Jones, J. D., and Brown, J. K. (2006). Multiple avirulence paralogues in cereal powdery mildew fungi may contribute to parasite fitness and defeat of plant resistance. Plant Cell 18, 2402-2414. doi: 10.1105/tpc.106.043307

Saunders, D. G., Win, J., Cano, L. M., Szabo, L. J., Kamoun, S., and Raffaele, S. (2012). Using hierarchical clustering of secreted protein families to classify and rank candidate effectors of rust fungi. PLOS ONE 7:e29847. doi: 10.1371/journal.pone.0029847

Stergiopoulos, I., Collemare, J., Mehrabi, R., and de Wit, P. J. (2013). Phytotoxic secondary metabolites and peptides produced by plant pathogenic Dothideomycete fungi. FEMS Microbiol. Rev. 37, 67-93. doi: 10.1111/j.15746976.2012.00349.x

Svircev, A., Biggs, A., and Miles, N. (1991). Isolation and partial purification of phytotoxins from liquid cultures of Leucostoma cincta and Leucostoma persoonii. Can. J. Bot. 69, 1998-2003. doi: 10.1139/b91-251

Vleeshouwers, V. G., and Oliver, R. P. (2014). Effectors as tools in disease resistance breeding against biotrophic, hemibiotrophic, and necrotrophic plant 
pathogens. Mol. Plant Microbe Interact. 27, 196-206. doi: 10.1094/MPMI-1013-0313-IA

Wang, Q., Han, C., Ferreira, A. O., Yu, X., Ye, W., Tripathy, S., et al. (2011a). Transcriptional programming and functional interactions within the Phytophthora sojae RXLR effector repertoire. Plant Cell 23, 2064-2086. doi: 10.1105/tpc.111.086082

Wang, X., Wei, J., Huang, L., and Kang, Z. (2011b). Re-evaluation of pathogens causing Valsa canker on apple in China. Mycologia 103, 317-324. doi: 10.3852/09-165

Wang, X., Jiang, N., Liu, J., Liu, W., and Wang, G. L. (2014). The role of effectors and host immunity in plant-necrotrophic fungal interactions. Virulence 5, 722-732. doi: 10.4161/viru.29798

Yin, Z., Ke, X., Huang, D., Gao, X., Voegele, R. T., Kang, Z., et al. (2013). Validation of reference genes for gene expression analysis in Valsa mali var. mali using real-time quantitative PCR. World J. Microbiol. Biotechnol. 29, 1563-1571. doi: 10.1007/s11274-013-1320-6

Yin, Z., Liu, H., Li, Z., Ke, X., Dou, D., Gao, X., et al. (2015). Genome sequence of Valsa canker pathogens uncovers a potential adaptation of colonization of woody bark. New Phytol. doi: 10.1111/nph.13544 [Epub ahead of print].

Yu, J., Hamari, Z., Han, K., Seo, J., Reyes-Domínguez, Y., and Scazzocchio, C. (2004). Double-joint PCR: a PCR-based molecular tool for gene manipulations in filamentous fungi. Fungal Genet. Biol. 43, 973-981. doi: 10.1016/j.fgb.2004.08.001
Zhou, X., Zhang, H., Li, G., Shaw, B., and Xu, J. R. (2012). The cyclaseassociated protein Cap1 is important for proper regulation of infectionrelated morphogenesis in Magnaporthe oryzae. PLoS Pathog. 8:e1002911. doi: 10.1371/journal.ppat.1002911

Zhou, Y., Zhang, M., Zhai, L., Yang, X., Cao, S., Hong, N., et al. (2014). Comparison of pathogenicity of Valsa mali strains showing different culturing phenotypes. Acta Phytopathol. Sin. 44, 217-220.

Zhu, W., Wei, W., Fu, Y., Cheng, J., Xie, J., Li, G., et al. (2013). A secretory protein of necrotrophic fungus Sclerotinia sclerotiorum that suppresses host resistance. PloS ONE 8:e53901. doi: 10.1371/journal.pone.0053901

Conflict of Interest Statement: The review editor Weixing Shan declares that, despite being affiliated with the same institution as authors Zhiyuan Yin, Xu Ming, and ZhenPeng Li, the review process was carried out objectively. The authors declare that the research was conducted in the absence of any commercial or financial relationships that could be construed as a potential conflict of interest.

Copyright (C) 2015 Li, Yin, Fan, Xu, Kang and Huang. This is an open-access article distributed under the terms of the Creative Commons Attribution License (CC BY). The use, distribution or reproduction in other forums is permitted, provided the original author(s) or licensor are credited and that the original publication in this journal is cited, in accordance with accepted academic practice. No use, distribution or reproduction is permitted which does not comply with these terms. 